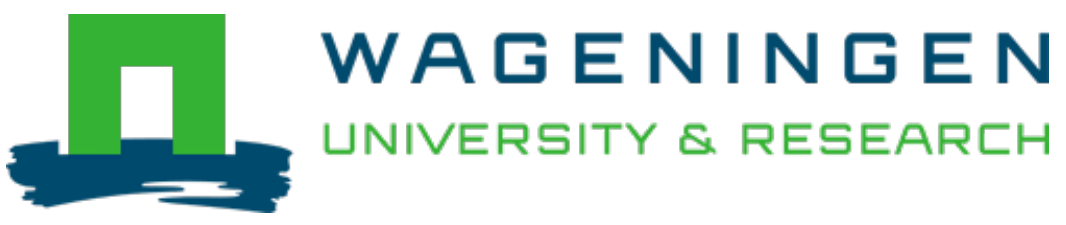

\title{
Energetic Ethics. Georges Bataille in the Anthropocene
}

\section{Global Changes}

Zwier, J.; Blok, V.

https://doi.org/10.1007/978-3-030-29443-4_15

This article is made publicly available in the institutional repository of Wageningen University and Research, under the terms of article $25 \mathrm{fa}$ of the Dutch Copyright Act, also known as the Amendment Taverne. This has been done with explicit consent by the author.

Article $25 \mathrm{fa}$ states that the author of a short scientific work funded either wholly or partially by Dutch public funds is entitled to make that work publicly available for no consideration following a reasonable period of time after the work was first published, provided that clear reference is made to the source of the first publication of the work.

This publication is distributed under The Association of Universities in the Netherlands (VSNU) 'Article $25 \mathrm{fa}$ implementation' project. In this project research outputs of researchers employed by Dutch Universities that comply with the legal requirements of Article $25 \mathrm{fa}$ of the Dutch Copyright Act are distributed online and free of cost or other barriers in institutional repositories. Research outputs are distributed six months after their first online publication in the original published version and with proper attribution to the source of the original publication.

You are permitted to download and use the publication for personal purposes. All rights remain with the author(s) and / or copyright owner(s) of this work. Any use of the publication or parts of it other than authorised under article $25 \mathrm{fa}$ of the Dutch Copyright act is prohibited. Wageningen University \& Research and the author(s) of this publication shall not be held responsible or liable for any damages resulting from your (re)use of this publication.

For questions regarding the public availability of this article please contact openscience.library@wur.nl 


\title{
Chapter 15 \\ Energetic Ethics. Georges Bataille in the Anthropocene
}

\author{
Jochem Zwier and Vincent Blok
}

\begin{abstract}
In this chapter, we develop the claim that today, in light of the distributed catastrophe called the Anthropocene, the question of ethics first and foremost becomes a question of economy and energy. Supplementing existing ethical approaches to the question of economy and energy, we offer what we understand to be a more fundamental economical interpretation of the Anthropocene by way of Georges Bataille's philosophical thought on economy. We will argue that inasmuch as it results from what has come to be known as "the great acceleration", the Anthropocene can be understood as a consequence of an economic consideration of energy that is oriented towards scarcity and utility, which is to say to Bataille's "restricted economy". Additionally, we show how for Bataille, such a 'restricted' consideration of energy is an ethical affair, since it misunderstands the constitutive abundance of energy associated with "the general economy", thereby simultaneously and catastrophically misunderstanding the ethos of human existence in servile terms of labour and efficiency. Finally, we investigate how Bataille's concept of sovereignty seeks to surpass such servility and efficiency by way of a consideration of energy that is oriented towards expenditure. We offer a reinterpretation of the ethics of sovereignty by confronting it with our contemporary deteriorating oikos inhabited in the Anthropocene. We close by arguing that notwithstanding its irrevocable difficulties, the question of ethics in the Anthropocene must be considered as an energetic ethics of sovereignty.
\end{abstract}

Keywords Anthropocene $\cdot$ Georges Bataille $\cdot$ General economy $\cdot$ Energy $\cdot$ Ethos

J. Zwier

Institute for Science in Society,

Radboud University Nijmegen, Nijmegen, The Netherlands

e-mail: jochem.zwier@ru.nl

V. Blok (凶)

Management Studies Chair Group and Philosophy Chair Group,

Wageningen University, Wageningen, The Netherlands

e-mail: vincent.blok@wur.nl 


\subsection{The Anthropocene. Ethics, Energy, and Economy}

The preeminent global change that confronts ethical thought today goes by the name of the Anthropocene. In leaving no part of our globe untouched, the Anthropocene stirs up a fundamental ethical question, not only in terms of what we must do, but also in terms of who we must be, of our character or ethos as Earthlings. In outlining the relevance of energy, the present chapter offers a way of responding to this ethical question.

What, first of all, is the Anthropocene? While many differing interpretations of the concept have been generated (Lorimer 2017), they all generally understand the Anthropocene as the epoch in which humanity becomes the dominant factor shaping the Earth and its associated life-supporting systems (Steffen et al. 2007). Succeeding the Holocene, where a relatively warm climate was considered to be the foremost geological factor (Crutzen 2002; Fagan 2004; Dumanoski 2009), the Anthropocene forefronts the techno-industrial activity of anthropoi or humans, thus marking the time in which "natural and human forces [are] intertwined, so that the fate of the one determines the fate of the other" (Zalasiewicz et al. 2010, 2231). As emphasized by Clive Hamilton and his colleagues, this is not exclusively the scientific concern of climate science, geology, or Earth-system science. Rather, the Anthropocene more generally "represents the ground-breaking attempt to think together earth processes, life, [and] human enterprise [...] into a totalizing framework" (Hamilton et al. 2015, 2).

According to such a totalizing framework, human enterprise no longer merely registers as a force unfolding on Earth, but comes under consideration as Earth, which is to say as an earth-shaping force of considerable, even dominant magnitude (Zwier and Blok 2017). This magnitude, markedly expressed in the global demographic growth depicted in Fig. 15.1, concomitantly indicates the Anthropocene's central problem, since humanity's vast influence heats up the Earth-system to the extent that

Fig. 15.1 Population growth-"the great acceleration" (image source: Steffen et al. 2015, 84)

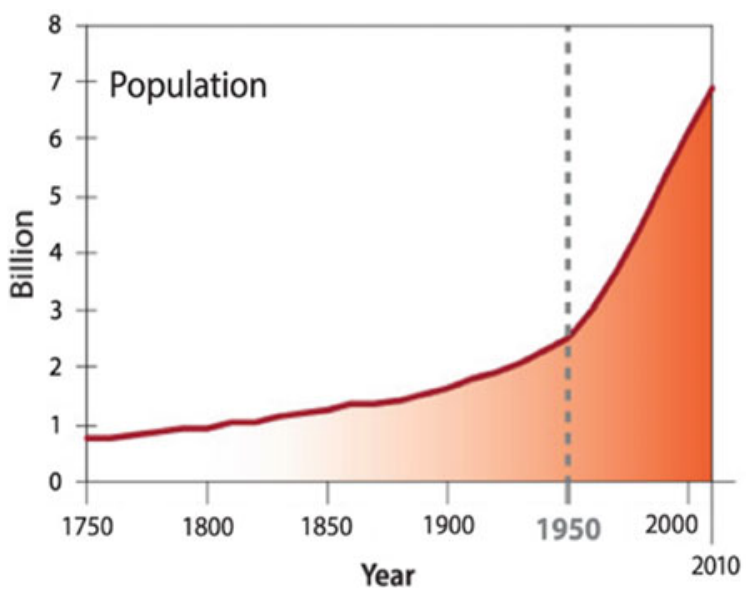


Fig. 15.2 Atmospheric $\mathrm{CO}_{2}$ at Mauna Loa observatory (image source: https://www. esrl.noaa.gov/gmd/ccgg/ trends/full.html)

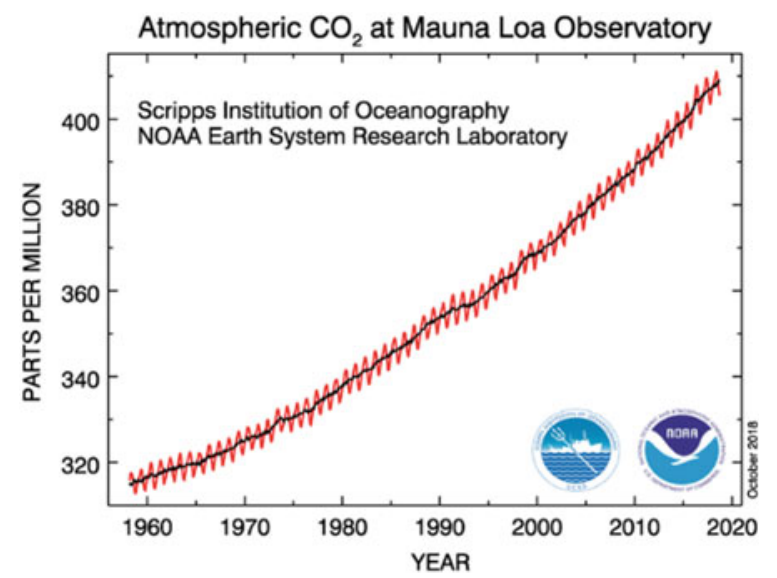

its habitability becomes endangered, the gravity of which is perhaps best expressed in Fig. 15.2, depicting global warming.

Both Figs. 15.1 and 15.2 are bolstered by the energy depicted in Fig. 15.3, given how demographic expansion has been made possible by large-scale exploitation of fossil forms of energy such as coal and oil, whilst this self-same exploitation led to an overall rise in global temperatures. The issue of energy therefore presents a central tenet of the Anthropocene in general, and for its ethical implications in particular.

It may therefore come as no surprise that numerous ethical considerations of the Anthropocene cluster around the issue of energy, many of which relate it to economy. To name a few instances, one may think of the skewed distribution of economic wealth gained from the local exploitation of fossil fuels in the global North, versus its detrimental climatic effects on the globe as such (cf. Baskin 2015; Shue 2010). One may critically evaluate capitalist tendencies to ruthlessly exploit energy sources for profit, and point to neglected costs of environmental devaluation. Finally (yet of course far from exhaustively), one can think of ethical issues related to moving to

Fig. 15.3 Primary energy use- "the great acceleration" (image source: Steffen et al. 2015, 84)

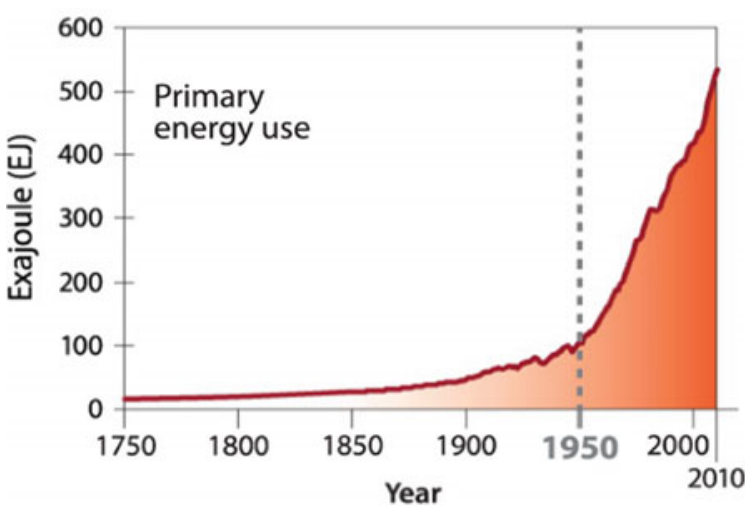


an energetically sustainable economy: who pays, profits, which values are taken into account and which are ignored, etc. (Parry 2007; Blok and Lemmens 2015).

While such ethical considerations address the issue of energy and the Anthropocene in many different ways, they share a common denominator of considerable import, namely that they address energy as a particular thing or good that exists within an economy. As a result of this basic assumption, ethical reflection comes to concern the normative dimension of the way in which energetic goods are economically exploited, appraised, valued, distributed, etc. Now, without belittling such considerations or denying them their place in the ethical and political discourse surrounding the Anthropocene, it is significant to note that they tend to bypass an equally relevant and more rudimentary interpretation of the relation between energy and economy.

Georges Bataille's philosophical contemplation of energy and economy offers such a rudimentary interpretation, and thus serves to situate the abovementioned understanding of energy (as an economic good) within a more general economic and energetic framework. As will become clear, his contemplation thereby raises an ethical consideration that differs from the ones sketched above, and turns out to be of central relevance to the issue of the Anthropocene.

\subsection{Bataille: Energy and Economy}

In thinking of energy and economy, Bataille introduces a distinction between what he calls "the restricted economy" and "the general economy" (Bataille 1991). The restricted economy corresponds to how we usually conceive of economy, which is to say as a system of production and consumption of goods that is characterized by scarcity, neediness, and associated useful production. The economic logic is familiar here: scarcity of goods engenders demand, which elicits labour to address needs and overcome scarcity by way of producing useful goods. For example, we need electrical energy to power our homes, and must therefore engage in an economy of production and consumption of the scarce good of electrical energy. Such an engagement may accordingly raise the aforementioned ethical issues, for instance with regards to "green energy", sustainability, etc. For Bataille, the restricted economy thereby implies a particular understanding of the world, a "consciousness of necessity, of an indigence," according to which individuals like our colloquial selves come into view as "nothing but eternally needy individuals" (Bataille 1991, 23).

Yet as its name suggests, Bataille considers the restricted economy to concern only a particular, restricted situation within the much larger framework of "the general economy" (Bataille 1991, 20). The latter concerns the flow of energy in general, where energy is not-and this is a cardinal difference compared to the restricted economy - considered as a good existing within a particular economy. Rather, energy is what first constitutes and literally sets in-operation all processes and activities of life on the surface of the globe, including particular economic processes involving the production and consumption of goods. 
A second cardinal difference is that from the perspective of general economy, energy is not primarily characterized by scarcity and exigence, but by abundance and excess. This concretely means that the energetic abundance of the sun constitutes natural organisms and propels life on the surface of the Earth. Bataille takes it as "a basic fact" that because the influx of solar energy is unremitting, natural organisms receive more energy than strictly required for maintaining life, resulting in excess energy (Bataille 1991, 21). He articulates this excess in terms of "pressure" (Bataille 1991, 29-36), the first effect of which is expansion, as this reduces pressure via spatial distribution. If otherwise unhindered, growth eventually runs up against spatial limits, and since the sun remains impartial to such limits and continues to relentlessly bestow its energizing gift, surplus energy can eventually no longer be incorporated via growth, but must be dissipated. For Bataille, therefore, "the impossibility of continuing growth makes way for squander" (Bataille 1991, 29) via "the production of increasingly burdensome forms of life" (Bataille 1991, 33). Where, for instance, plants make relatively efficient use of the sun's gift for growth, ${ }^{1}$ so called higher organisms eat plants and other animals without growing to the same extent, thus making self-preservation and growth a more burdensome or expensive affair. Additionally, the extravagant, intricate, and painstakingly extensive sexual behaviours of higher organisms imply a relatively inefficient way of procreation. In short, for Bataille: "The mammalian organism is a gulf that swallows vast quantities of energy" (Bataille 1986, 60). To be clear, none of this denies that natural life occasionally faces energetic shortages and accordingly engages in a struggle for survival, but Bataille interprets such a struggle as both constituted by, and partaking in the general movement of energy that is characterized by abundance and ultimately by squander. A hungry lion may face a shortage of food, but its hunting and eating of a zebra (which itself "swallows vast quantities of energy" by inefficiently feeding on grass) partakes in the carnivorous squander of the abundant energy that constitutes the grass, the zebra, and the lion.

Bataille's general economy thus concerns the abundant energy that constitutes all living beings on Earth, including human beings. At the same time, humans occupy a unique position in this energetic constellation. Like all organisms, humanity is exposed to abundant solar energy, yet by tapping into fossil sources of energy like coal and oil (as well as nuclear energy), humanity exposes itself to energetic abundance even more. As a consequence of unlocking ever greater energy resources and using only a fraction of this resource for self-maintenance, humanity faces an increasing surplus of energy. As with other lifeforms, this engenders demographic expansion and spatial distribution of humans on Earth.

\footnotetext{
${ }^{1}$ Although relatively efficient (in comparison to higher organisms), plants also involve their own 'burdensome' ways, e.g. the fruitless sexuality of flowering plants (Wendlin 2007, 39).
} 


\subsection{Bataille and the Anthropocene}

This brief sketch of Bataille's thought already indicates its relevance to the topic of the Anthropocene. On the one hand, Bataille can be seen as an Anthropocenic thinker avant la lettre. If we recall Hamilton's abovementioned idea that the Anthropocene places human enterprise and other earthly dynamics into one totalizing framework, it may be clear how Bataille anticipates this idea inasmuch as he positions human beings within the energetic framework of the general economy, in which all life on the planet is implicated.

On the other hand, the Anthropocene can be understood as the concrete outcome of the unique way in which humanity is implicated in the general economy. If, following Bataille, energetic abundance engenders pressure which in turn effects expansion, the Anthropocene can be seen as its result (cf. Zwier and Blok 2019). Whatever its exact starting point (Lorimer 2017) it is clear that the Anthropocene involves an enormous increase of human beings on the planet since that point (recall Fig. 15.1). This increase is itself made possible by the tremendous accumulation, production, and transformation of energetic resources that modern, industrialized humanity accomplishes (recall Fig. 15.3). It is through this energetic accomplishment that now, in the Anthropocene, humanity takes the stage as the dominant earthshaping force.

Be that as it may, this accomplishment is not simply a matter of abundant energy as such, but first and foremost concerns the way in which it is addressed and understood. In elucidating this point, it is relevant to note how Bataille characterizes modern, industrial human existence by a tendency to forget the general economy and its constitutive, abundant energy. ${ }^{2}$ Due to this forgetfulness, the modern understanding of the world exclusively follows the logic of the restricted economy and its aforementioned "consciousness of necessity." This implies turning a blind eye to energetic abundance, only to consider questions of economy and energy in terms of scarcity and the need for efficient, productive labour. ${ }^{3}$ Our present-day colloquial understanding of economy attests to this hegemony of the restricted economy, given how we unquestioningly take for granted the need to engage in productive labour to "make a living," i.e. compensate for insufficient economic resources. The same goes for mainstream economic science inasmuch as it is self-evidently oriented towards the complex dynamics of scarcity of production (Zwier et al. 2015). Due to the hegemony of the restricted economy, energy solely comes under consideration as a scarce good for which there exists a continuous and increasing demand. In response, energy is produced and mobilized in ever increasing amounts, with ever increasing efficiency, ultimately resulting in what Fig. 15.3 illustrates.

\footnotetext{
${ }^{2}$ The dialectical movement that undergirds Bataille's consideration of such forgetfulness is beyond the scope of the present chapter (Gemerchak 2003).

${ }^{3}$ We cannot here repeat Bataille's (quasi-Weberian) analysis of the development of such forgetfulness, in which the rise of protestantism, capitalism, and industrialism are central (Bataille 1991, particularly 115-141).
} 
According to this Bataillean interpretation then, the Anthropocene distinctly comes into view as an energetic and economic affair. It appears as the outcome of the way in which human existence forgets the general economy, instead of adhering to the hegemonic logic of the restricted economy. The accompanying emphasis on efficiency and productivity gives rise to an economic growth that now reaches planetary proportions.

\subsection{Energetic Ethics}

Bataille's economic thought has an ethical character inasmuch as it addresses what he calls the "failure of humanity" (Bataille 2007, 15) to take heed of the general economy. In exclusively adhering to the restricted economy and thus solely addressing energy in terms of its efficient production, humanity becomes increasingly exposed to the abundant influx and pressure of the general economy. As with any living system, this causes expansion. But where the logic of the restricted economy celebrates such expansion under the heading of economic growth, Bataille stresses that all growth must eventually run out of space. When this happens, pressure builds up, and like any limited system that is subjected to increasing pressure, it finally explodes. Writing in the aftermath of two world wars which he understands as "the greatest orgies of wealth that history has recorded" (Bataille 1991,37), Bataille imagines—with Argus' eyes-the eruption of another war as the explosive and catastrophic outcome of (or rather outlet for) uncontainable pressure. As with other constituents of the general economy, "the impossibility of continuing growth makes way for squander" (Bataille $1991,29)$, which in the case of forgetful human existence takes the catastrophic form of war.

For Bataille therefore, the failure of neglecting the general economy "causes us to undergo what we could bring about in our own way" (Bataille 1991, 23). This failure evidently concerns ethics, and Bataille explicitly aims to find better ways of dealing with excess energy, of "exhausting the surplus without war" (Bataille 2007, 428). In exploring cultural history, he famously finds examples of pressure exhausts in the ritual of potlach, where the indigenous people in the American northwest wasted surplus energy by way of the destruction of accumulated and produced resources, for instance by wrecking one's canoes, up to setting one's own village on fire (Bataille 1991, 67-68). Other examples include pyramids as an energetically inefficient burial method (119), Lamaist monks who avoided activity in contemplative life, thus dissipating the surplus generated by Tibetan workers (Bataille 1991, 93-110), jewels, works of art (Bataille 1989; Wendlin 2007, 39), and most eminently eroticism (Bataille 1986, 2007). All of these indicate a different approach to energy: rather than considering it a scarce good to be accumulated and put to work, they acknowledge rather than forget its constitutive abundance, accordingly attesting to how "it is not necessity but its contrary, 'luxury' that presents living matter and mankind with their fundamental problems" (Bataille 1991, 12). For Bataille, such luxury is a fundamental ethical problem, given how refraining from burning off 
excess energy eventually causes humanity to undergo its catastrophic dissipation in war.

The Anthropocene, however, complicates this problem. The reason for this is that Bataille does not take the ecological crisis into consideration. His analysis relies on a stable Earth-system upon which the human habitat is subjected to pressure, grows, and eventually either bursts out in war, or finds better ways of dissipating excess energy. However, where Bataille is concerned with burning of excess energy, the Anthropocene forefronts the aftermath of the excessive burning of fossil fuels. ${ }^{4}$ This is to say that in light of global warming, the already peculiar call for the dissipative burning of excess energy appears even more unacceptable. There are nonetheless at least two reasons why Bataille's thought remains relevant for an ethics of energy in the Anthropocene.

First, it is worth noting how many responses to the Anthropocene and ecological crisis frame the core energetic problem as one of economic efficiency. In attempting to confront "a world with growing pressures on resources and the environment", initiatives like the Bio-Based Economy aim for the "transition to a resource-efficient and ultimately regenerative circular economy" (European Commission 2012, 1). Such a bio-based, circular economy is thereby envisioned as an "efficient economic system that produces no waste" (Asveld et al. 2011, 11). Accordingly, the ideals of circularity and "zero-waste" imply that energetic resources (e.g. biomass) are renewable and can always be mobilized for further use. In light of the above, it may come as a surprise that such an ideal quite explicitly adheres to Bataille's restricted economy, given how (bio)energy is solely addressed as a scarce good that cannot be wasted, but must continuously be put to work. Now, on the one hand, it goes without saying that the Anthropocene compels us to take serious consideration of such initiatives. On the other hand, Bataille's thought compels the critical question whether ideals like the bio-based economy are not short-sighted, and whether they do not merely offer momentary reprieve. An economic ideal that seeks after absolute efficiency whilst excluding any form of waste or squander cannot but result in an economy that must grow under the pressure of the (forgotten) general economy. It thus repeats Bataille's "human failure" as it eventually moves towards a cataclysmic dissipation of surplus energy, a bio-based catastrophe. ${ }^{5}$ Therefore, even in the harrowing light of global warming, Bataille's fundamental economic problem of luxury and its dissipation cannot simply be discounted.

Secondly, Bataille's ethical challenge remains relevant for the Anthropocene insofar as it raises the question concerning our character or ethos as Earthlings. Inasmuch as it articulates an approach to energy that calls for its useless expenditure and thus moves beyond the means-end relation according to which energy is primarily useful,

\footnotetext{
${ }^{4}$ Alan Stoekl offers an instructive contextualization which explains why ecology was not a primary concern for Bataille (Stoeckl 2007). However, where Stoeckl confronts Bataille with the depletion of fossil fuels, the Anthropocene primarily concerns the aftermath of their combustion. Indeed, it is now becoming increasingly clear that our present stockpile of fossil fuels suffices to render the planet uninhabitable (Bonneuil 2015, 26).

${ }^{5}$ For an elaborate analysis of Bataille and the Bio-Based Economy, cf. Zwier et al. (2015); see also Painter-Morland et al. (2017).
} 
Bataille's contemplation of economy ultimately raises the question whether human existence must be primarily characterized in terms of usefulness and efficiency. For Bataille, the expenditure witnessed in pyramids, religious festivals, eroticism, and artworks involves an ecstatic and rapturous experience that carries consciousness beyond its usual and restricted "consciousness of necessity." Although the associated squander of energy may serve to fend off catastrophic war, this is never its final use and legitimation. Rather, it indicates the possibility of a domain beyond utility altogether.

Strange and fleeting as this idea may be-and Bataille is well aware that his suggestions "go against the judgments that form the basis of a rational economy" and require a "reversal of thinking" (Bataille 1991, 22-25) — it forms a worthwhile complement to contemporary ethical considerations of the Anthropocene. Whereas many such considerations (quite rightly) concern the way in which energy and economy can be aligned according to a manner that fosters a good and sustainable way of maintaining our collective livelihoods, Bataille's thought accentuates the horizon of such efforts. It confronts us with the question whether existence is principally characterized by (ethically honourable) self-maintenance and sustainability, or whether the need for self-maintenance is itself to be transgressed. Particularly now, when the survival of humankind can no longer be taken for granted, questioning the horizonboth energetic and ethical—of self-maintenance appears a worthwhile endeavour.

\section{References}

Asveld L, van Est R, Stemerding D (2011) Executive summary. In: Asveld L, van Est R, Stemerding $\mathrm{D}$ (eds) Getting to the core of the bioeconomy: a perspective on the sustainable promise of biomass. Rathenau Institute, The Hague, pp 11-14

Baskin J (2015) Paradigm dressed as epoch: the ideology of the Anthropocene. Environ Values 24:9-29

Bataille G (1986) Erotism: death and sensuality (Trans: Dalwood M). City Lights Books, San Francisco

Bataille G (1989) The tears of Eros (Trans: Connor, P). City Light Books, San Fransisco

Bataille G (1991) The accursed share, vol. I (Trans: Hurley R). Zone Books, New York

Bataille G (2007) The accursed share vol II \& III (Trans: Hurley R). Zone Books, New York

Blok V, Lemmens P (2015) The emerging concept of responsible innovation; three reasons why it is questionable and calls for a radical transformation of the concept of innovation. In: Koops B-J, Oosterlaken I, Romijn H, Swierstra T, van den Hoven J (eds) Responsible innovation. Vol. 2. concepts, approaches, and applications. Springer, Dordrecht, pp 19-35

Bonneuil C (2015) The geological turn: narratives of the Anthropocene. In: Hamilton C, Bonneuil $\mathrm{C}$, Gemenne F (eds) The Anthropocene and the global environmental crisis. Routledge, London, pp 17-31

Crutzen PJ (2002) Geology Of mankind: the Anthropocene. Nature 415:23

Dumanoski D (2009) The end of the long summer: why we must remake our civilization to survive on a volatile Earth. Three Rivers Press, New York

European Commission (2012) Manifesto for a resource-efficient Europe. Available via: http:// europa.eu/rapid/press-release_MEMO-12-989_en.htm. Accessed 1 Oct 2018

Fagan B (2004) The long summer: how climate changed civilisation. Basic Books, Cambridge 
Gemerchak CM (2003) The sunday of the negative. Reading Bataille Reading Hegel. SUNY Press, New York

Hamilton C, Bonneuil C, Gemenne F (2015) Thinking the Anthropocene. In: Hamilton C, Bonneuil $\mathrm{C}$, Gemenne F (eds) The Anthropocene and the global environmental crisis. Routledge, London, pp 1-13

Lorimer J (2017) The Anthroposcene: a guide for the perplexed. Soc Stud Sci 47(1):117-142

Painter-Morland M, Demuijnck G, Ornati S (2017) Sustainable development and well-being: a philosophical challenge. J Bus Ethics 146(2):295-311

Parry B (2007) Cornering the futures market in "Bio-epistemology". BioSocieties 2(3):386-389

Shue H (2010) Subsistence emissions and luxury emissions. In: Gardiner SM, Caney S, Jamieson D, Shue H (eds) Climate ethics: essential readings. Oxford University Press, New York

Steffen W, Crutzen PJ, McNeill JR (2007) The Anthropocene: are humans now overwhelming the great forces of fature? Ambio 36(8):614-621

Steffen W, Broadgate W, Deutsch L, Gaffney O, Ludwig C (2015) The trajectory of the Anthropocene: the great acceleration. Anthropos Rev 2(1):81-98

Stoekl A (2007) Bataille's peak: energy, religion, and postsustainability. University of Minnesota Press, Minneapolis

Wendlin AE (2007) Sovereign consumption as a species of communist theory. In: Winnubst $\mathrm{S}$ (eds) Reading Bataille now. Bloomington \& Indianapolis: Indiana University Press, pp 35-53

Zalasiewicz J, Williams M, Steffen W, Crutzen PJ (2010) The new world of the Anthropocene. Environ Sci Technol 44:2228-2231

Zwier J, Blok V, Lemmens P, Geerts R-J (2015) The ideal of a zero-waste humanity: philosophical reflections on the demand for a bio-based economy. J Agric Environ Ethics 28(2):353-374

Zwier J, Blok V (2017) Saving Earth: encountering Heidegger's philosophy of technology in the Anthropocene. Techné: Res Philos Tech. https://doi.org/10.5840/techne201772167

Zwier J, Blok V (2019) Seeing through the fumes: technology and asymmetry in the Anthropocene. Hum Stud. https://doi.org/10.1007/s10746-019-09508-4 